\title{
Duration of visible persistence in relation to stimulus complexity
}

\author{
DAVID E. IRWIN and JAMES M. YEOMANS \\ Michigan State University, East Lansing, Michigan
}

\begin{abstract}
Visible persistence refers to the phenomenal impression that a stimulus is still present after its offset. A dispute exists whether visible persistence is due to temporal sluggishness in the visual pathway (neural hypothesis) or whether it is a byproduct of information-extraction processes under cognitive control ( $p r o c e s s$ hypothesis). This was investigated by manipulating stimulus complexity in five temporal integration experiments and one recognition memory experiment. According to the process hypothesis, complex stimuli should persist longer than simple stimuli because they require more information extraction. This prediction was not confirmed; in all six experiments, complexity was found to have no reliable effect on the duration of visible persistence. By contrast, and in accordance with earlier findings, complexity was shown to have a significant effect on a short-lived, nonvisible form of memory known as schematic persistence. This pattern of results supports two major conclusions: First, that the effects of complexity reported in earlier research were probably on schematic-rather than visible-persistence; and second, that visible persistence must be regarded as a residual neural trace of an extinguished stimulus, rather than as a byproduct of information-extraction processes.
\end{abstract}

Visible persistence refers to the phenomenal, lingering trace of a stimulus after its offset. Some investigators, such as Coltheart (1980) and Eriksen and Schultz (1978), have suggested that visible persistence is due to residual neural activity in the visual pathway. According to this neural view, visible persistence results from temporal sluggishness in the visual system. In other words, it is an automatic event initiated by stimulus onset whose duration is determined by physical characteristics of the stimulus such as its intensity and its duration. Other investigators, however, such as Erwin (1976a, 1976b), Erwin and Hershenson (1974), Loftus and Hanna (1989), and Loftus and Hogden (1988), have challenged this view on the basis of experiments whose results suggest that the amount of information contained in a stimulus affects how long it appears to persist after its offset. This result has been taken as evidence for a process model of visible persistence in which persistence duration is determined by the processing demands of higher level cognitive operations, such as stimulus encoding. According to this view, visible persistence is a byproduct of ongoing information-

This article is based on a master's thesis submitted by the second author to Michigan State University. The research was supported by Grants BNS 85-19580 and BNS 89-08699 from the National Science Foundation to David E. Irwin. Portions of the data were presented at the annual meeting of the Midwestern Psychological Association, Chicago, IL in May 1986. We thank David Van Dyk and Jennifer Larys for assistance with data collection and Tom Carr and Jim Zacks for helpful comments regarding the research. Vince Di Lollo and two anonymous reviewers made helpful comments on an earlier version of the manuscript. Requests for reprints may be directed to David E. Irwin, who is now at the Department of Psychology, University of Ilinois at UrbanaChampaign, 603 East Daniel, Champaign, IL 61820. extraction processes, rather than a fading neural aftereffect of the extinguished stimulus. On this account, the perceptual system maintains a visible trace of the stimulus for as long as it takes to extract information from it. The purpose of the present research was to contrast these two competing accounts of visible persistence. We did this by examining the effect of stimulus complexity on the duration of visible persistence. If visible persistence is a passive, automatic process that is initiated by stimulus onset, then stimulus complexity should have little effect on the duration of visible persistence. On the other hand, if visible persistence is a consequence of informationextraction processes, then more complex stimuli (which contain more information) should persist longer than less complex stimuli.

Several investigations have addressed this issue before, but with mixed results. Evidence favoring the neural model of persistence was provided by Phillips (1974). In his experiments, subjects made same/different judgments of patterns created by randomly filling cells in a square matrix. Pattern complexity was manipulated by varying the number of elements in the pattern (e.g., 8 vs. 32). In Phillips's experiments, one pattern was presented for $1 \mathrm{sec}$, then it was followed some variable time later by a second pattern that was either identical to the first or different by the addition or deletion of one element. Subjects judged whether the two patterns were identical or different. Phillips found that pattern complexity had little effect on accuracy when the temporal interval separating the two patterns was less than $100 \mathrm{msec}$. This suggests the existence of a complexity-independent representation operating shortly after stimulus offset, consistent with the neural model of visible persistence. One problem with this 
conclusion, however, is that Phillips used an exposure duration of $1 \mathrm{sec}$, and many investigators have found that visible persistence is negligible for stimulus exposures greater than $100 \mathrm{msec}$ or so (see Coltheart, 1980, for a review). Thus, it is not clear that the complexityindependent representation isolated by Phillips (1974) corresponds to visible persistence.

Furthermore, several other studies have found evidence for a complexity effect on early visual processing, consistent with the process view of visible persistence. For example, Avant, Lyman, and Antes (1975) found that familiarity affected the apparent duration of a stimulus. In their experiments, two stimuli were presented for $30 \mathrm{msec}$ each, separated by a $1-\mathrm{sec}$ interval. Subjects reported which of the two stimuli appeared to have a longer duration. Letters, words, and nonwords were used as stimuli. Avant et al. found that nonwords were judged to have a longer duration than words, which were judged to have a longer duration than letters. When a word was inverted, thereby reducing its familiarity, its apparent duration increased substantially. Additional research by Avant and Lyman (1975) showed that repeated presentations of a stimulus, which should increase its familiarity, led to a decrease in its apparent duration. Thus, these findings suggest that less familiar (and hence more complex) stimuli persist longer than more familiar stimuli, consistent with the process view of visible persistence. But although these experiments indicate that stimulus complexity affects some aspect of early visual processing, it is unlikely that this effect occurs by increasing the duration of visible persistence. This is demonstrated by the Avant et al. (1975) finding that the differences in perceived duration between stimuli were more substantial when a noise mask was presented during the interframe interval; if complexity exerts its effect by increasing the duration of visible persistence, then the differences in perceived duration between stimuli should have disappeared rather than become larger when a mask that eliminated visible persistence was presented after stimulus offset. Consequently, Avant and colleagues suggested instead that the differences in perceived duration that they found were a consequence of faster access to the internal representations of familiar stimuli, rather than to differences in the duration of visible persistence.

Several other studies provide more direct support for the process view of visible persistence, however. For example, Loftus and Hanna (1989) collected ratings of subjective completeness for various visual stimuli that had been divided randomly into two halves, which were then presented in rapid temporal succession. The two stimulus halves appeared to form a complete, or whole, stimulus as long as visible persistence from the first half was available during the blank interval separating the two stimulus halves. Loftus and Hanna found that increasing the temporal separation between the stimulus halves had a larger detrimental effect on the subjective completeness of simple dot patterns than on the subjective completeness of complex scenes, consistent with the idea that complex stimuli persist longer than do simple stimuli. How- ever, as Loftus and Hanna pointed out, their dot and scene stimuli differed on other dimensions as well (e.g., contrast, luminance), so it is not clear what role, if any, stimulus complexity played in their experiment.

Several other studies have used an onset-offset reactiontime task to assess the duration of visible persistence for different kinds of stimuli. In this task, the mean of a series of reaction times to the onset of a visual display is subtracted from the mean of a series of reaction times to the offset of the display. The difference (minus stimulus exposure duration) is an estimate of the duration of visible persistence for that display. Briggs and Kinsbourne (1972) found that a display consisting of squares persisted for a shorter period of time than a display consisting of letters, although this difference did not reach significance. If one assumes that letters are more complex than squares (because letters contain more features and more identity codes than does a uniform field of squares), this result is consistent with the process view of visible persistence.

Similar studies have been conducted by Erwin and Hershenson (1974) and by Erwin (1976b). Erwin and Hershenson used the onset-offset reaction-time technique to measure the visible persistence of three kinds of stimuli: a blank field, a dark field, and a field containing seven letters. Erwin and Hershenson found that the field of letters persisted 35 msec longer than the blank field and the dark field (which did not differ from each other) when report of the letters in the array was required; no differences were found when report was not required. Erwin (1976b) replicated this finding and also discovered that the redundancy of the letter string (i.e., its approximation to English) affected persistence duration when report was required, such that more redundant strings persisted for a shorter time than less redundant (i.e., more complex) strings. Erwin concluded that the information content of a stimulus affects its persistence, but only when the information in the stimulus must be utilized.

The reliability of the onset-offset reaction-time technique as a means of measuring the duration of visible persistence has recently been questioned by several investigators (e.g., Coltheart, 1980; Long, 1980), however, casting doubt on the conclusions of Briggs and Kinsbourne (1972), Erwin (1976b), and Erwin and Hershenson (1974). Of particular concern is the possibility of criterion shifts across experimental conditions. That is, letters and blank fields may persist visibly for the same amount of time, but a subject's criterion for "display offset" may vary with information load. This potential problem is illustrated most clearly by Long and Wurst (1984). Using an offset reaction-time task, Long and Wurst found that persistence duration increased with increasing complexity in one experiment, but decreased with increasing complexity in another. Because much of the data supporting the process view of persistence has come from experiments using the onset-offset reaction-time technique, questions about its reliability weaken the support for the process view.

In summary, the evidence regarding neural versus process views of visible persistence is quite ambiguous. One possible reason for this ambiguity stems from the use 
of subjective measures of visible persistence such as the onset-offset reaction-time technique. In the research described below, a more objective method for measuring visible persistence was used in an effort to discriminate between the neural and process hypotheses. Specifically, we used a temporal integration task first employed by Hogben and Di Lollo (1974), who elaborated on a method used by Eriksen and Collins (1967). In this task, two halves of a matrix of elements are presented in two frames of time, minus one element. The subject's task is to identify the location of the missing element. Accurate performance of this task is very difficult unless the first half of the matrix persists long enough to be integrated with the second half of the matrix when it is presented. Thus, correct report of the missing element's location is an objective indication of the existence of visible persistence. To test between the neural and process accounts of visible persistence, we varied the complexity of the stimulus elements in the matrix to see whether more complex stimuli could be integrated over longer time periods than less complex stimuli. Such a result would provide support for the process view of visible persistence.

\section{EXPERIMENT 1}

In this experiment, 24 of the 25 elements from a $5 \times 5$ array were presented in two frames of time, 12 elements per frame. A variable time interval separated the presentation of the two frames. The subject's task was to identify the location in the $5 \times 5$ matrix at which no element had been presented. Half of the trials were designated as high-complexity trials, and the array elements in this case were randomly chosen consonants (excluding y). The other trials were designated as low-complexity trials, and the array elements in this case consisted entirely of Xs. The random-letter arrays were assumed to be more complex (i.e., less redundant) than the X-arrays at both a cognitive level and at a featural level. At a cognitive level, random-letter arrays are more complex because they contain many more letter identities; at a featural level, the $\mathrm{X}$-arrays contained only left-slanted and right-slanted diagonals, whereas the random-letter arrays contained a variety of features.

\section{Method}

Subjects. Six subjects participated in this experiment. They were drawn from the Michigan State University community (as were the subjects in all of the subsequent experiments) and they included undergraduates, graduate students, and faculty. The subjects had little or no knowledge of the experimental hypotheses. All subjects reported normal or corrected-to-normal vision, and each was paid $\$ 1.50$ for each of four $1 / 2-h$ sessions.

Apparatus and Stimuli. Stimuli were displayed on a HewlettPackard 1340A X-Y oscilloscope (P31 phosphor) driven by a Digital Equipment Corporation Micro-11/23+ computer through digitalto-analog converters. The computer also recorded subject responses entered on the terminal keyboard. The experimental chamber was illuminated throughout the experiment to prevent the subjects from detecting phosphor persistence. The stimuli were presented with an effective luminance of $61 \mathrm{~cd} / \mathrm{m}^{2}$; the background luminance of the display screen was $12 \mathrm{~cd} / \mathrm{m}^{2}$.
The subjects viewed the oscilloscope at a distance of $33 \mathrm{~cm}$, set by a chinrest. At this distance, each element in the array subtended $0.3^{\circ}$ horizontally and $0.4^{\circ}$ vertically; the spaces between elements subtended $0.4^{\circ}$ vertically and horizontally. Thus, the entire matrix subtended $3.1^{\circ}$ horizontally and $3.6^{\circ}$ vertically.

To equate the random-letter arrays and the $X$-arrays for brightness, each $X$ was constructed using 16 light points, the average number used in constructing letters.

Procedure. Figure 1 summarizes the sequence of events on each experimental trial. Following a keypress, a fixation point was presented for $500 \mathrm{msec} ; 500 \mathrm{msec}$ later, the first frame of 12 elements appeared for $20 \mathrm{msec}$. Following an interframe interval of variable duration $(10,30,50,70,90$, or $120 \mathrm{msec})$, the second frame of 12 elements then appeared for $20 \mathrm{msec}$. Following Frame 2 presentation, the subject entered the row and column coordinates of the location at which no element had been presented. Feedback $(+$ or -$)$ was presented on the oscilloscope screen for $500 \mathrm{msec}$.

The complexity of the stimulus array (i.e., random letters vs. all Xs) varied randomly from trial to trial, as did the interframe interval. The two frames of the array always contained the same

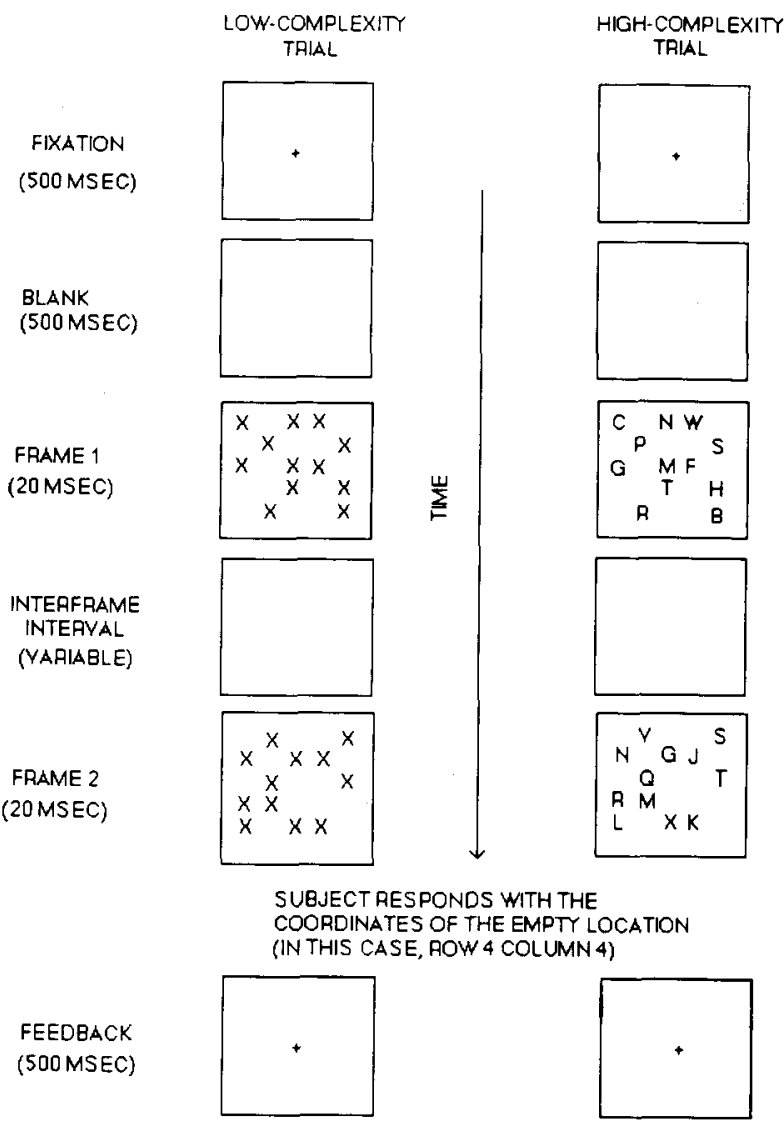

Figure 1. Schematic illustration of the procedure in Experiment 1. The subject initiated each trial by making a keypress. This resulted in presentation of a fixation point for $\mathbf{5 0 0}$ msec. Following a $\mathbf{5 0 0}$ msec blank interval, 12 randomly chosen elements from a $5 \times 5$ matrix were presented for 20 msec. Then a variable interframe interval elapsed before 12 additional elements from the matrix were presented for 20 msec. Across the two stimulus frames, 24 of the 25 positions in the matrix were occupied; the subject's task was to report the coordinates of the unoccupled location. Following this response, feedback was given for 500 msec. On low-complexity trials, the array elements were all Xs; on high-complexity trials, the array elements were randomly chosen consonants. 


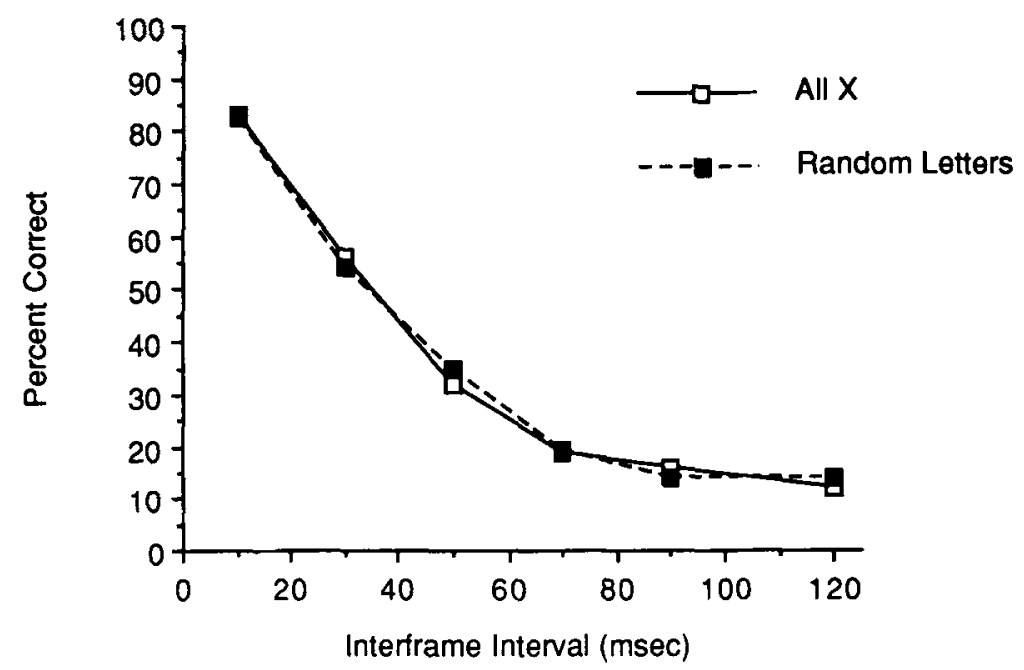

Figure 2. Percent correct as a function of interframe interval for low-complexity (all Xs) and high-complexity (random-letter stimuli) trials in Experiment 1.

stimulus type. Each subject completed 1,200 trials over four sessions, consisting of 100 trials at each of the two complexity levels at each of the six interframe intervals.

\section{Results and Discussion}

The results of Experiment 1 are shown in Figure 2. An analysis of variance (ANOVA) (4 sessions $\times 2$ levels of complexity $\times 6$ interframe intervals) revealed that accuracy improved over sessions $[F(3,15)=7.9, p<.005]$ and accuracy declined with increases in interframe interval $[F(5,25)=37.1, p<.001]$. The complexity main effect was not significant $[F(1,5)=0.10, p\rangle .75]$. No interactions were significant (all $F_{\mathrm{S}}<1.1$ ). As Figure 2 shows, the results for random-letter arrays and $\mathrm{X}$-arrays were virtually identical. The standard error for the data plotted in Figure 2 was $<2 \%$, smaller than the data symbols in the figure; this was true for all the experiments reported in this paper.

The results of this experiment suggest that stimulus complexity has no effect on the duration of visible persistence. These data thus support the view that visible persistence results from residual neural activity in the visual pathway, rather than from information-extraction processes that actively control its duration.

It is possible, however, that we have simply not manipulated complexity effectively. This seems unlikely, because the random-letter arrays were much more variable than the X-arrays in terms of letter features and letter identities. This definition of complexity is consistent with several previously proposed complexity metrics, such as number of interior angles in the figure (Attneave, 1957), symmetry (Garner \& Clement, 1963), and level of uncertainty (Shannon \& Weaver, 1949). But to bolster the case for the neural explanation of visible persistence, the experiments that follow manipulated complexity in several different ways. If no effects of stimulus complexity on temporal integration are found, this will lend substantial credence to the neural view of visible persistence.

\section{EXPERIMENT 2}

As mentioned in the introduction, several previous investigations have indicated that stimulus familiarity affects the apparent duration of a stimulus (e.g., Avant et al., 1975; Erwin, 1976b). In Experiment 2, we investigated this factor using the temporal integration task employed in Experiment 1. A set of pseudoletters was created by rearranging the lines that made up the letter stimuli, and integration performance for arrays of randomly chosen letters was compared with integration performance for arrays of randomly chosen pseudoletters. If the process view of visible persistence is correct, then unfamiliar pseudoletters should persist longer than familiar letters and accuracy for the pseudoletter arrays should be higher than accuracy for the letter arrays. The neural hypothesis, however, predicts no difference in integration performance for the different stimulus types.

\section{Method}

Subjects. Seven subjects participated in this experiment. All reported normal or corrected-to-normal vision, and each was paid $\$ 5$ for a single session lasting approximately $1.5 \mathrm{~h}$.

Apparatus and Stimuli. The apparatus used in Experiment 1 was used in Experiment 2. Arrays of randomly chosen consonants (excluding y) or randomly chosen pseudoletters (created by the second author by rearranging the line segments of each of the 20 letters used) were used as stimuli. Figure 3 illustrates the pseudoletters that were used.

As in Experiment 1, each trial involved the presentation of two frames of elements; together, the two frames filled in 15 of the 16 locations in a $4 \times 4$ matrix. The first frame contained 8 elements in randomly determined positions from the matrix, while the second frame contained 7 elements. The two frames always contained the same type of stimulus (letters vs. pseudoletters). 


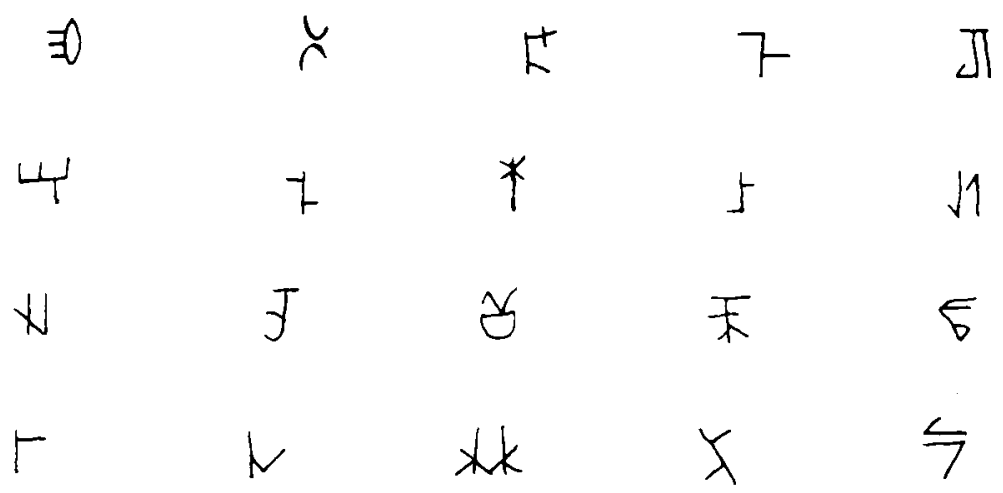

Figure 3. Pseudoletters used in Experiments 2 and 3.

The subjects viewed the display from a distance of $33 \mathrm{~cm}$, set by a chinrest. The letters and pseudoletters subtended $0.3^{\circ}$ horizontally and $0.4^{\circ}$ vertically. The spaces between the stimulus elements subtended $0.4^{\circ}$ vertically and horizontally. The entire array subtended $2.8^{\circ}$ vertically and $2.4^{\circ}$ horizontally. The letters and the pseudoletters were equated for the number of light points they contained, which averaged 16 points. The stimulus and background luminances were the same as in Experiment 1. Pseudoletters were assumed to be more complex than letters because of their unfamiliarity.

Procedure. The experimental procedure was very similar to that in Experiment 1. The first frame of eight elements was presented for $20 \mathrm{msec}$. Following a variable interframe interval $(10,40,70$, 100,130 , or $160 \mathrm{msec}$ ), the second frame of seven elements was presented for $20 \mathrm{msec}$. The subject reported the location in the $4 \times 4$ matrix at which no element had been presented by typing its row and column coordinates on the computer terminal keyboard. Stimulus type and interframe interval varied randomly from trial to trial. Each subject completed two blocks of 300 trials each, constituting 50 trials at each of the two complexity levels at each of the six interframe intervals. In addition, the subjects completed 30 practice trials before the first block of experimental trials and 20 practice trials before the second block of experimental trials.

\section{Results and Discussion}

The results of this experiment are shown in Figure 4. Analysis of variance revealed that the main effect of interframe interval was significant $[F(5,30)=74.0$, $p<.001]$ : accuracy decreased as interframe interval increased. The complexity effect was not significant $[F(1,6)$ $=1.6, p>.25]$, nor was the complexity $\times$ interframe interval interaction $[F(5,30)=0.8, p>.5]$. No other main effects or interactions were significant.

Although there was no statistically significant effect of complexity in this experiment, inspection of Figure 4 suggests that integration accuracy for the letter displays was slightly worse than integration accuracy for the pseudoletter displays for interframe intervals of $100 \mathrm{msec}$ and less. In other words, the function for the letter stimuli lags slightly behind the function for the pseudoletter stimuli. Thus, it is possible that there was some small effect of stimulus complexity on the duration of visible persistence that we were unable to detect statistically. Loftus (1985; Loftus \& Bamber, 1990) has argued that the horizontal

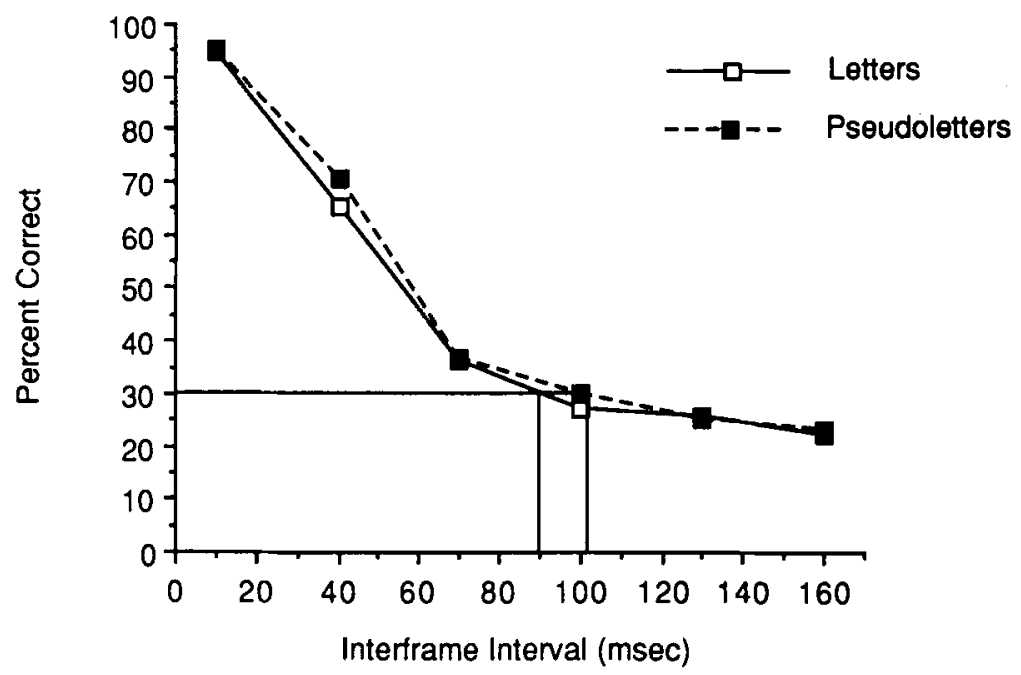

Figure 4. Pencent correct as a function of interframe interval for low-complexity (letter stimuli) and high-complexity (pseudoletter stimuli) trials in Experiment 2. The additional horizontal and vertical lines in the figure were used to estimate the interframe intervals at which the forgetting functions for the letter and pseudoletter stimuli reached $30 \%$ accuracy. 
displacement between forgetting curves, rather than their vertical displacement (which is what an ANOVA is sensitive to), is a more appropriate measure of differences in forgetting rate between experimental conditions. According to Loftus, one needs to consider how long it takes performance in different memory conditions to fall from one level of accuracy to another, rather than comparing performance in different memory conditions at different points in time. In the present case, to determine whether pseudoletter stimuli persist longer than letter stimuli, it is necessary to estimate how long it takes letter and pseudoletter integration performance to fall from perfect accuracy to some lower level of accuracy; we chose $30 \%$ as this lower level of accuracy because performance in both conditions appears to approach asymptote near this level. In Figure 4, a horizontal line depicting 30\% accuracy has been drawn from the $y$-axis to the functions corresponding to letter and pseudoletter performance, and from there down to the $x$-axis. By interpolating between points on the $x$-axis, it is possible to estimate how long it took integration accuracy to fall to $30 \%$ for the letter and pseudoletter stimuli. When letters were used as stimuli, integration accuracy fell to $30 \%$ when an interframe interval of $90 \mathrm{msec}$ separated the two halves of the stimulus matrix. When pseudoletters were used as stimuli, however, integration accuracy did not reach $30 \%$ until the interframe interval reached 102 msec. Thus, when one considers the horizontal displacement (in milliseconds) between the letter curve and the pseudoletter curve near their asymptotes, it appears that pseudoletter stimuli persisted about $12 \mathrm{msec}$ longer than letter stimuli. Because pseudoletter stimuli are less familiar, and hence more complex, than letter stimuli, the results of this experiment provide some support for the process view of visible persistence.

One problem with comparing forgetting curves in the way suggested by Loftus is that it is difficult to make statistical tests on horizontal differences between the forgetting functions (Bogartz, 1990; Loftus, 1985; Loftus \& Bamber, 1990). It is inappropriate to use the error term from the ANOVA because it is based on vertical variability between points, rather than on horizontal variability between functions. Thus it is difficult to assess the significance of the 12-msec difference between the letter and pseudoletter forgetting functions at the $30 \%$ accuracy level. We attempted to do this by examining the forgetting functions for individual subjects. That is, for each of our 7 subjects we created a plot like that shown in Figure 4 , and then we examined these plots to determine whether the forgetting function for letters reached asymptote more quickly than did the forgetting function for pseudoletters. For 4 subjects, the forgetting function for letters reached asymptote more quickly than did the forgetting function for pseudoletters; for three subjects the reverse was true. This is not significant by a sign test. Thus, the 12-msec difference between the letter and pseudoletter functions was not general across subjects; we conclude that it is not statistically reliable.
To summarize, this experiment, unlike Experiment 1 , found some evidence for a familiarity or complexity effect on the duration of visible persistence, but this effect was small and it did not generalize across subjects. Given that some evidence for a complexity effect was found, however, it is worthwhile to examine further the influence of stimulus familiarity on the duration of visible persistence. This was the purpose of Experiment 3.

\section{EXPERIMENT 3}

Experiment 3 was a replication of Experiment 2, except for a change in the size of the stimulus display. Di Lollo and Hogben (1985) recently demonstrated that the duration of visible persistence is affected by suppressive interactions among elements appearing close together in space and time. In their experiments, subjects were shown displays in which a point stepped around a circular path on an oscilloscope. Because of visible persistence, more than one point appeared to be present at a time. Subjects estimated the number of points they could see simultaneously, thereby providing a measure of the duration of visible persistence (cf. Allport, 1970). Di Lollo and Hogben found that the duration of visible persistence was highly dependent on interpoint separation; suppression of visible persistence occurred when successive points were separated by less than $0.5^{\circ}$. This suppression appeared to be similar to metacontrast masking (e.g., Breitmeyer \& Ganz, 1976; Matin, 1975; Weisstein, Ozog, \& Szoc, 1975). Di Lollo and Hogben (1987) varied interpoint separation in a temporal integration task very similar to the one employed in the present research and demonstrated that interelement suppression occurs in this task as well. Because the array elements in Experiments 1 and 2 were separated by less than $0.5^{\circ}$, it is possible that interelement suppression influenced the duration of visible persistence in these studies. Although the pseudoletter stimuli were constructed by rearranging the "features" of the letter stimuli, it is conceivable that the two sets of stimuli might create different amounts of interelement suppression. This potential difference in interelement suppression between the letter and pseudoletter stimuli might have masked any effects of stimulus complexity on the duration of visible persistence in Experiment 2. To rule out this possibility, in Experiment 3 the spatial separation between the array elements was increased in order to reduce the influence of interelement suppression on the duration of visible persistence.

\section{Method}

Subjects. Seven subjects participated in this experiment. All reported normal or corrected-to-normal vision, and each was paid $\$ 5$ for each of two sessions lasting approximately $45 \mathrm{~min}$ each. None of the subjects had participated in Experiments 1 or 2 .

Apparatus and Stimuli. The apparatus used in the preceding experiments was used in Experiment 3. Arrays of randomly chosen consonants (excluding y) or randomly chosen pseudoletters (shown in Figure 3) were used as stimuli. 
As in Experiment 2, each trial involved the presentation of two frames of elements; together, the two frames filled in 15 of the 16 locations in a $4 \times 4$ matrix. The first frame contained 8 elements in randomly determined positions from the matrix, while the second frame contained 7 elements. The two frames always contained the same type of stimulus (letters vs. pseudoletters).

The subjects viewed the display from a distance of $33 \mathrm{~cm}$, set by a chinrest. The letters and pseudoletters subtended $0.3^{\circ}$ horizontally and $0.4^{\circ}$ vertically. The spaces between the stimulus elements subtended $1.0^{\circ}$ vertically and horizontally. At this separation, the effects of interelement suppression should be negligible. The entire array subtended $4.6^{\circ}$ vertically and $4.2^{\circ}$ horizontally. The stimulus and background luminances were the same as in the first two experiments.

Procedure. The experimental procedure was identical to that in Experiment 2. The first frame of eight elements was presented for $20 \mathrm{msec}$. Following a variable interframe interval $(10,40,70,100$, 130 , or $160 \mathrm{msec}$ ), the second frame of seven elements was presented for $20 \mathrm{msec}$. The subject reported the location in the $4 \times 4$ matrix at which no element had been presented by typing its row and column coordinates on the computer terminal keyboard. Stimulus type and interframe interval varied randomly from trial to trial. Each subject completed two blocks of 300 trials each, constituting 50 trials at each of the two complexity levels at each of the six interframe intervals. In addition, the subjects completed 30 practice trials before the first block of experimental trials and 20 practice trials before the second block of experimental trials.

\section{Results and Discussion}

The results of this experiment are shown in Figure 5. Analysis of variance revealed that the main effect of interframe interval was significant $[F(5,30)=63.6, p<$ .001 ]: accuracy decreased as interframe interval increased. The complexity effect was not significant $[F(1,6)$ $=1.3, p>.3]$, nor was the complexity $\times$ interframe interval interaction $[F(5,30)=1.3, p>.3]$.

Inspection of Figure 5 reveals no systematic difference in the horizontal displacement between the functions for letter and pseudoletter integration performance. As in Experiment 2 , the interframe interval that resulted in nearasymptotic performance (in this experiment, $25 \%$ accuracy) was estimated for both the letter and pseudoletter stimuli by interpolating between points on the $x$-axis. When letters were used as stimuli, integration accuracy fell to $25 \%$ when an interframe interval of $112 \mathrm{msec}$ separated the two halves of the stimulus matrix. When pseudoletters were used as stimuli, integration accuracy reached $25 \%$ at an interframe interval of $99 \mathrm{msec}$. Thus, unlike in Experiment 2, in this experiment the pseudoletter stimuli reached asymptote faster than the letter stimuli. This result was not general across subjects, however. For 4 of the subjects, integration accuracy for the letter stimuli reached asymptote faster than integration accuracy for the pseudoletter stimuli; for 3 of the subjects, the reverse was true. In summary, this experiment provides no support for the hypothesis that less familiar stimuli persist visibly for a longer duration than more familiar stimuli. It appears that the failure to find evidence for a complexity effect on persistence duration in Experiment 2 was not due to differences in interelement suppression between the letter and pseudoletter stimuli. In summary, the results of Experiments $\mathbf{2}$ and $\mathbf{3}$ are inconsistent with the process view of visible persistence.

\section{EXPERIMENT 4}

The first three experiments have provided results that are generally consistent with the hypothesis that visible persistence is simply a fading neural trace of an extinguished stimulus; stimulus complexity had no reliable effect on the duration of visible persistence, contrary to the predictions of the process view of visible persistence. A

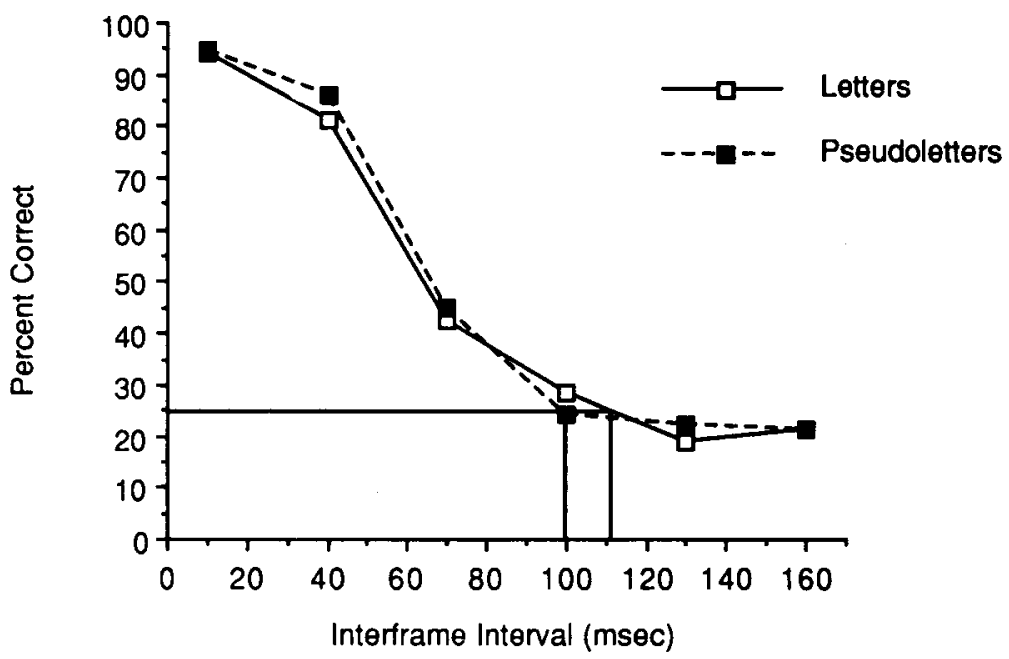

Figure 5. Percent correct as a function of interframe interval for low-complexity (letter stimuli) and high-complexity (pseudoletter stimuli) trials in Experiment 3. The additional horizontal and vertical lines in the figure were used to estimate the interframe intervals at which the forgetting functions for the letter and poeudaletter stimuli reached 25\% accuracy. 
proponent of the process view could argue, however, that these experiments have failed to show a complexity effect because they did not require identification or highlevel processing of the stimulus elements in the array. Erwin (1976b), for example, stressed that complexity effects on visible persistence were found only when the stimulus information had to be utilized in some way, such as in verbal report. To examine this possibility, in Experiment 4 we attempted to force identification of the stimuli while still maintaining the task of detecting the missing element in the stimulus array. The process hypothesis predicts that a complexity effect should appear in this experiment; the neural hypothesis predicts that this deeper processing requirement will have no effect on the duration of visible persistence.

\section{Method}

Subjects. Seven subjects participated in this experiment; 6 of them had participated in Experiment 3. All subjects reported normal or corrected-to-normal vision, and each subject was paid $\$ 5$ for each of four 1-h sessions.

Apparatus and Stimuli. The apparatus used in the previous experiments was used in this experiment. Arrays of randomly chosen consonants (excluding y) were used as stimuli. Complexity was varied by presenting the consonants in either an upright (lowcomplexity) or inverted (high-complexity) orientation. Inverting the letters reduces their familiarity, and Avant et al. (1975) found that inverted stimuli had a longer perceived duration than did upright stimuli. Thus, if complexity affects the duration of visible persistence, integration performance for the inverted letters should reach asymptote more slowly than integration performance for the upright letters.

As in the previous experiments, each trial involved the presentation of two frames of elements; together, the two frames filled in 15 of the 16 locations in a $4 \times 4$ matrix. The first frame contained 8 elements in randomly determined positions from the matrix, while the second frame contained 7 elements. The two frames always contained the same type of stimulus (upright letters vs. inverted letters).

The subjects viewed the display from a distance of $33 \mathrm{~cm}$, set by a chinrest. The letters subtended $0.3^{\circ}$ horizontally and $0.4^{\circ}$ vertically. The spaces between the stimulus elements subtended $0.4^{\circ}$ vertically and horizontally. The entire array subtended $2.4^{\circ}$ vertically and $2.8^{\circ}$ horizontally. The stimulus and background luminances were the same as in the previous experiments. Because the same elements (i.e., letters) were used on both low-complexity and high-complexity trials, any effects of interelement suppression were equated across complexity conditions.

Procedure. Each subject completed four experimental sessions. The experimental procedure during these sessions was very similar to that of the previous experiments, except that during two of the sessions (the report sessions), subjects reported the letters that had appeared in the same row as the missing element after they reported its row and column coordinates. That is, they performed a partial report of the array elements, with the missing element serving as the partial report cue. During the other two experimental sessions (the no-report sessions), subjects merely reported the row and column coordinates of the missing element. All reports were made by typing on the computer keyboard. Session type (report vs. no report) alternated across experimental sessions; order was counterbalanced across subjects.

Each subject completed 20 practice trials and 300 experimental trials during each experimental session. The 1,200 experimental trials consisted of $\mathbf{5 0}$ trials at each of the two complexity levels at each of the six interframe intervals, under report and no-report con- ditions. Stimulus type and interframe interval varied randomly from trial to trial.

\section{Results and Discussion}

Accuracy of letter report in the report condition is shown in Figure 6. A two-way ANOVA with factors of complexity (upright vs. inverted letters) and interframe interval $(10,40,70,100,130$, or $160 \mathrm{msec})$ showed that accuracy of letter report was highly dependent on interframe interval $[F(5,30)=30.7, p<.001]$; accuracy was highest (54\%) at the shortest interval and lowest (19\%) at the longest interval. The decline in accuracy with increasing interframe interval occurred for two reasons: First, accurately locating the missing element became more difficult as the interframe interval increased, and second, the letters that had appeared in the first frame decayed as the interframe interval increased. Report of the upright letters was more accurate than report of the inverted letters $[F(1,6)=10.2, p<.02]$, most likely because it is easier to identify upright than inverted letters. The interaction between stimulus complexity and interframe interval was also significant $[F(5,30)=7.1, p<$ $.001]$, reflecting the fact that the difference in report accuracy for upright vs. inverted letters was greater at the shortest interframe interval than at the longer intervals. These results indicate that subjects were trying to identify the letters in the stimulus matrix during the report trials; thus, if stimulus complexity increases the duration of visible persistence when stimuli are processed at a cognitive level, integration accuracy for the inverted letters should be higher than integration accuracy for the upright letters in the report condition. In addition, one might expect accuracy in the report condition to be higher than accuracy in the no-report condition, because subjects processed the stimuli more deeply in the report condition than in the no-report condition.

Figure 7 shows integration accuracy for upright and inverted letters under report and no-report conditions as a function of interframe interval. A three-way ANOVA with factors of report condition (no report vs. report), com-

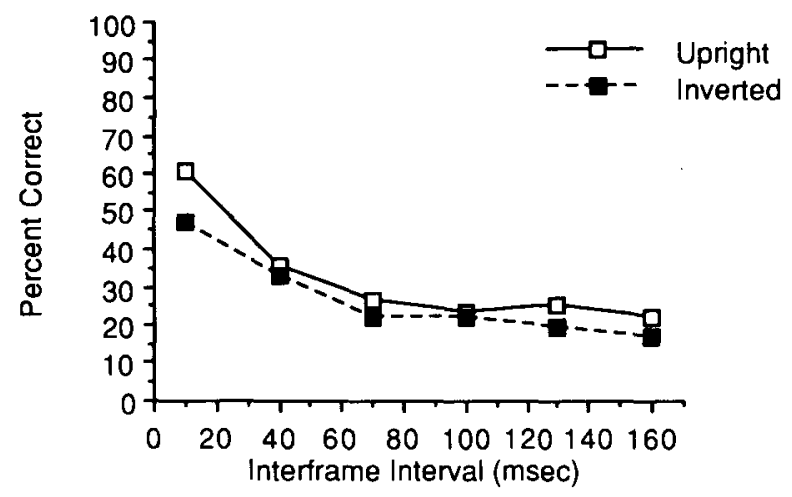

Figure 6. Percent correct report for upright and inverted letter arrays in the report condition of Experiment 4. 


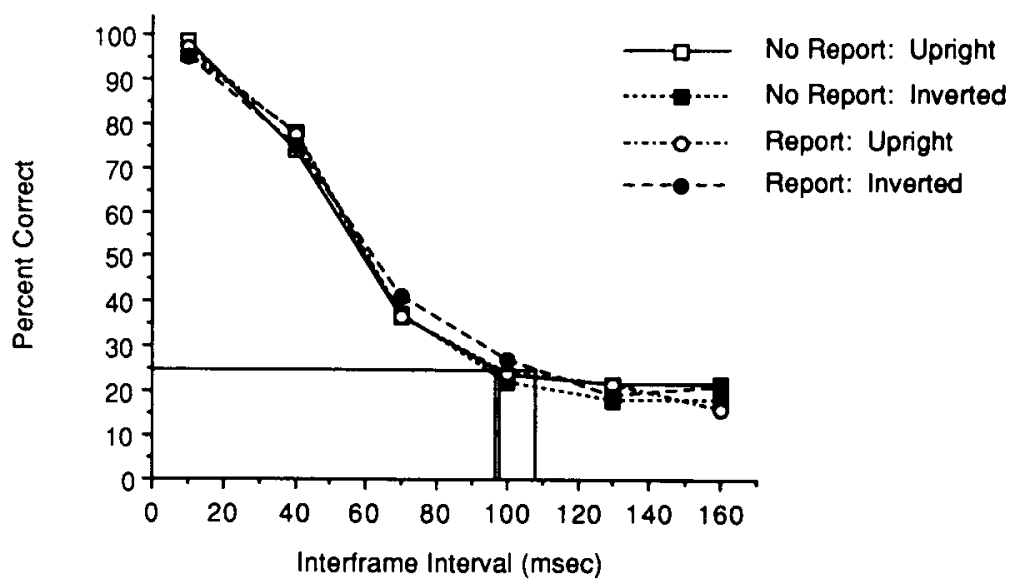

Figure 7. Percent correct as a function of interframe interval for low-complexity (upright letters) and high-complexity (inverted letters) trials under report and no-report conditions in Experiment 4. The additional horizontal and vertical lines in the ngure were used to estimate the interframe intervals at which the forgetting functions reached 25\% accuracy.

plexity (upright vs. inverted letters), and interframe interval $(10,40,70,100,130$, or $160 \mathrm{msec})$ revealed that integration accuracy decreased as interframe interval increased $[F(5,30)=75.7, p<.001]$. No other main effects or interactions were significant.

Inspection of Figure 7 suggests that integration performance for inverted letters in the report condition was slightly superior to integration performance in all other conditions. To estimate the size of this effect, the interframe interval that gave rise to an integration accuracy of $25 \%$ was estimated for upright and inverted stimuli under report and no-report conditions by interpolating between points on the $x$-axis. Integration accuracy for upright letters in the no-report condition fell to $25 \%$ when an interframe interval of $98 \mathrm{msec}$ separated the two halves of the stimulus matrix. For inverted letters in the no-report condition, integration accuracy reached $25 \%$ at an interframe interval of $96 \mathrm{msec}$. Thus, under no-report conditions, stimulus complexity had no discernible effect on the duration of visible persistence. In the report condition, however, integration accuracy for the upright letters fell to $25 \%$ when an interframe interval of $98 \mathrm{msec}$ separated the two halves of the stimulus matrix, whereas integration accuracy for inverted letters reached $25 \%$ at

Table 1

Interframe Intervals (in milliseconds) Corresponding to $25 \%$ Integration Accuracy for each Subject in each Condition of Experiment 4

\begin{tabular}{ccccc}
\hline Subject & $\begin{array}{c}\text { No Report: } \\
\text { Upright }\end{array}$ & $\begin{array}{c}\text { No Report: } \\
\text { Inverted }\end{array}$ & $\begin{array}{c}\text { Report: } \\
\text { Upright }\end{array}$ & $\begin{array}{c}\text { Report: } \\
\text { Inverted }\end{array}$ \\
\hline 1 & 48 & 57 & 70 & 63 \\
2 & 133 & 110 & 100 & 138 \\
3 & 70 & 93 & 93 & 93 \\
4 & 68 & 70 & 63 & 67 \\
5 & 112 & 94 & 120 & 112 \\
6 & 97 & 111 & 77 & 105 \\
7 & 92 & 95 & 138 & 95 \\
\hline
\end{tabular}

an interframe interval of 108 msec. This result provides some support for the process view of visible persistence; inducing subjects to process the stimulus information in the array more deeply by requiring a partial report had some influence on the duration of visible persistence, but the effect was rather small $(10 \mathrm{msec})$. Furthermore, it was not general across subjects. Table 1 shows the $25 \%$ accuracy interval for each subject in each condition of this experiment. Under no-report conditions, in 5 out of 7 cases the inverted stimuli persisted longer than the upright stimuli. Under report conditions, in 3 out of 7 cases the inverted stimuli persisted longer than the upright stimuli. These results are not significant by a sign test. Furthermore, the $25 \%$ accuracy intervals in the report conditions were not much different from those in the noreport conditions (98 msec vs. $98 \mathrm{msec}$ for upright letters, and $108 \mathrm{msec}$ vs. $96 \mathrm{msec}$ for inverted letters); for individual subjects, in only 7 out of 14 cases did persistence duration in the report condition exceed that in the corresponding no-report condition. If cognitive processing influences duration of visible persistence, its influence appears to be rather inconsequential and not general across subjects.

\section{EXPERIMENT 5}

The results of the first four experiments are generally consistent with the neural view of visible persistence: Duration of visible persistence was not reliably affected by stimulus complexity, even when subjects attempted to identify the stimulus elements. These results are contrary to the predictions of the process view of visible persistence. In the preceding experiments, stimulus complexity was manipulated by varying the redundancy or familiarity of the individual array elements; in Experiment 5, stimulus complexity was manipulated by varying the complexity of the overall pattern formed by the elements. This 
was accomplished by using a set of stimuli that had been independently rated for complexity. These ratings were reported in a recent study by Ichikawa (1985).

Ichikawa's (1985) subjects rated the complexity of 140 different arrangements of eight dots in $4 \times 4$ matrices. Two subsets of these patterns were used as the Frame 1 stimuli in Experiment 5: 40 patterns rated low in complexity, and 40 patterns rated high in complexity. If stimulus complexity affects the duration of visible persistence, then subjects should be able to integrate the high-complexity patterns over longer interframe intervals than the lowcomplexity patterns.

\section{Method}

Subjects. Twelve subjects participated in one version of this experiment, and each was paid $\$ 3$ for each of two 1-h sessions. Four of the subjects then completed two additional sessions with different experimental parameters for additional pay. All subjects reported normal or corrected-to-normal vision.

Apparatus and Stimuli. The apparatus used in the preceding experiments was used in this experiment. The Frame 1 stimuli in this experiment consisted of eight dots arrayed in a $4 \times 4$ matrix of locations. Forty patterns rated low in complexity and 40 patterns rated high in complexity were used as the Frame 1 stimuli. Patterns 26-65 from Table 2 of Ichikawa (1985) were used as the low-complexity stimuli; these patterns had a mean complexity rating of 2.96 (out of 7) with a range of 2.4-3.6. Patterns 101-140 from the same source were used as the high-complexity stimuli; these patterns had

\section{Simple}

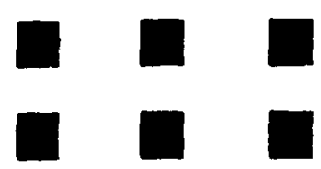

\section{Complex}

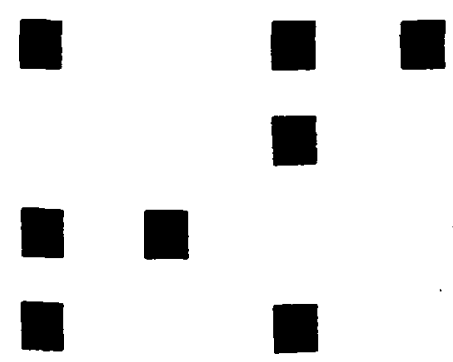

Figure 8. Example of simple and complex patterns used in Experiment 5. a mean complexity rating of 6.15 with a range of 5.5-6.7. Figure 8 shows examples of simple and complex patterns.

As in the previous experiments, each trial involved the presentation of two frames of elements; together, the two frames filled in 15 of the 16 locations in a $4 \times 4$ matrix. The first frame consisted of one of the Ichikawa (1985) 8-dot patterns, either a simple or a complex pattern, and the second frame was formed by randomly filling in 7 of the 8 remaining array locations.

The subjects viewed the display from a distance of $33 \mathrm{~cm}$, set by a chinrest. Each dot subtended $0.04^{\circ}$ of visual angle, and the spaces between dots subtended $0.8^{\circ}$ horizontally and $0.9^{\circ}$ vertically. At these separations, the effects of interelement suppression should be negligible. The entire array subtended $2.9^{\circ}$ vertically and $2.6^{\circ}$ horizontally. The stimuli were presented with an effective luminance of $71 \mathrm{~cd} / \mathrm{m}^{2}$; the background luminance was $12 \mathrm{~cd} / \mathrm{m}^{2}$.

Procedure. The experimental procedure was similar to that employed in the previous experiments. The first frame of eight dots was presented for $10 \mathrm{msec}$. Following a variable interframe interval $(10,30,50,70,85$, or $100 \mathrm{msec})$, the second frame of seven dots was presented for $10 \mathrm{msec}$. The subject reported the location in the $4 \times 4$ matrix at which no element had been presented by typing its row and column coordinates on the computer terminal keyboard. Stimulus type and interframe interval varied randomly from trial to trial. Each of the 12 subjects completed two sessions of 240 trials each, constituting 40 trials at each of the two complexity levels at each of the six interframe intervals (i.e., each subject saw each Frame 1 pattern once at each interframe interval).

Following the completion of these two experimental sessions, 4 of the subjects completed two additional experimental sessions that employed a wider range of interframe intervals $(10,40,70,100$, 130 , and $160 \mathrm{msec}$ ) and more experimental trials per condition. Each of these 4 subjects completed 960 trials, constituting 80 trials at each of the two complexity levels at each of the six interframe intervals; each subject saw each Frame 1 pattern twice at each interframe interval.

\section{Results and Discussion}

The results of both versions of this experiment are shown in Figure 9. Analysis of variance revealed that the main effect of interframe interval in Version 1 (12 subjects) was significant $[F(5,55)=52.6, p<.001]$; this effect was significant in Version 2 (4 subjects) as well $[F(5,15)=27.0, p<.001]$. Accuracy decreased as interframe interval increased. No other main effects or interactions were significant.

Inspection of Figure 9 reveals that stimulus complexity had only small effects on persistence duration; performance with the complex stimuli was slightly better than performance with the simple stimuli in Version 1 of the experiment, but the reverse was true in Version 2. No consistent patterns were present in the individual subject's data. Thus, the results of Experiment 5 converge with those of the previous experiments in providing no evidence for a complexity effect on the duration of visible persistence. This experiment, like the previous four experiments, is more consistent with the neural hypothesis of visible persistence than with the process hypothesis.

\section{EXPERIMENT 6}

The first five experiments used a temporal integration task to investigate the effects of several different manipulations of stimulus complexity on the duration of visible 

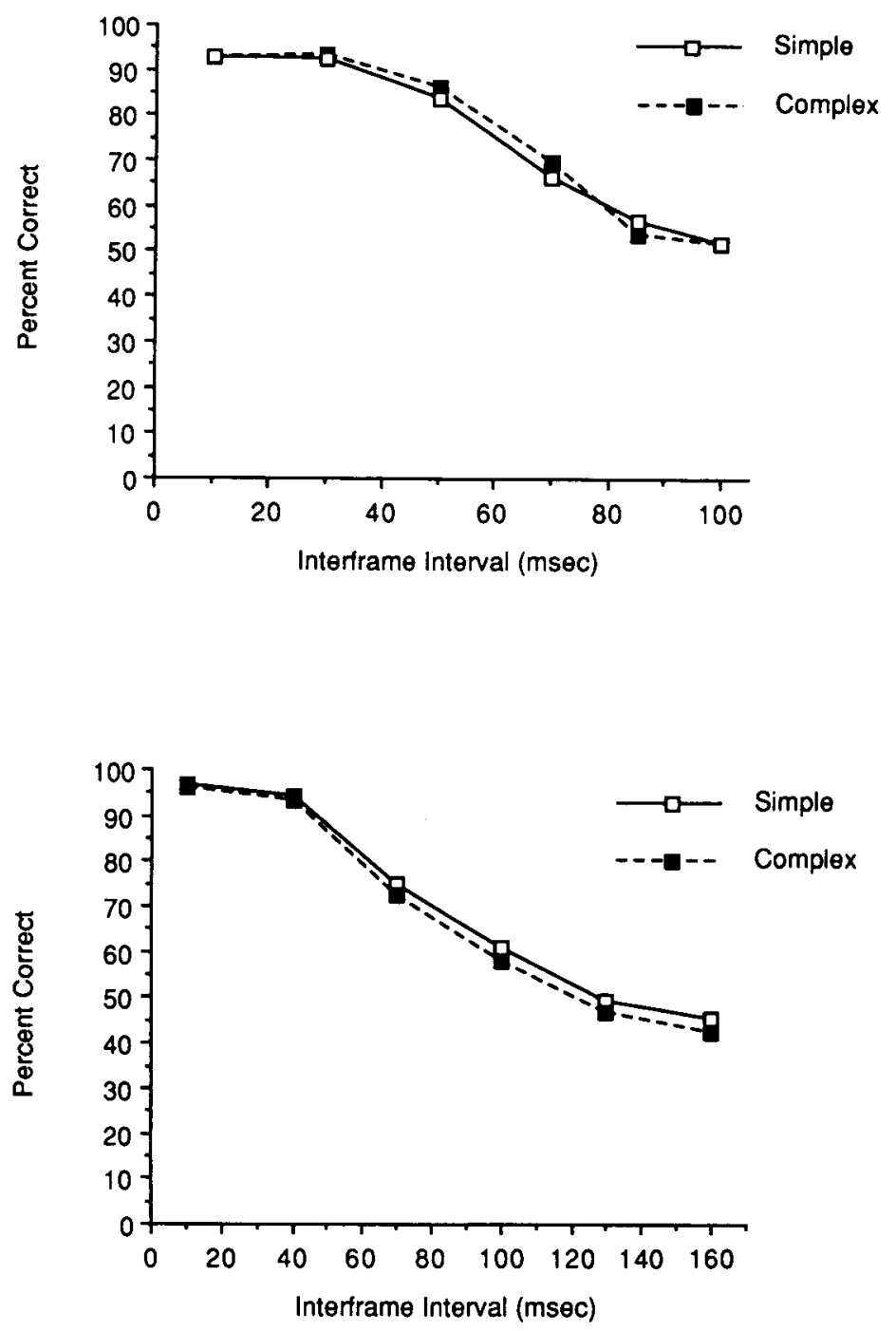

Figure 9. Percent correct as a function of interframe interval for simple and complex patterns in Experiment 5. The top panel contains the results for the first version of this experiment, which used 12 subjects and interframe intervals ranging from 10 to 100 msec. The bottom panel contains the results for the second version of this experiment, which used 4 subjects and interframe intervals ranging from 10 to 160 msec.

persistence. No evidence was found to support the hypothesis that complex stimuli persist visibly for a longer duration than simple stimuli. A concern, however, is whether complexity has been manipulated effectively in these experiments. The complexity variations that were employed were based on those used by previous investigators, so they have at least face validity. The conclusion that complexity has no effect on the duration of visible persistence would be strengthened by a demonstration that at least one of our complexity manipulations affects some form of visual memory, however. The purpose of Experiment 6 was to provide such a demonstration.

Experiment 6 employed the same/different recognition memory task that Phillips (1974) used to study the properties of sensory memory and visual short-term memory.
In Phillips's experiments, subjects made same/different judgments of random-dot patterns. One pattern was presented for $1 \mathrm{sec}$, then a second pattern was presented some variable time later. Phillips found that recognition memory was nearly perfect when a short interval (20 msec) separated the two displays, but accuracy declined as interpattern interval increased. Accuracy was still above chance for interpattern intervals as long as $9 \mathrm{sec}$, however. In addition, accuracy at short intervals was unaffected by the number of dots in each pattern (i.e., pattern complexity), but it was greatly disturbed by displacing the second pattern in space or by presenting a masking stimulus during the interpattern interval. At longer interpattern intervals (300 msec and greater), however, masking and stimulus displacement had little 
effect on accuracy but pattern complexity had a major effect, such that simple patterns were judged more accurately than complex patterns. These results provide support for two kinds of visual memory: One is a quickly decaying, high-capacity, maskable store tied to retinal position (sensory memory), and the other is a long-lasting, limited-capacity store that is nonmaskable and not tied to retinal position (visual short-term memory). However, as noted in the introduction, because the duration of the first pattern was $1 \mathrm{sec}$ in the Phillips (1974) experiments, it is unclear whether the "sensory memory" studied by Phillips is identical to visible persistence (Phillips himself made this point). Thus, the effect of stimulus complexity on visible persistence in the Phillips task is open to question.

To address this question, in Experiment 6 the dot patterns used in Experiment 5 (i.e., dot patterns varying in rated complexity) were used as stimuli to determine whether they would have any effect on performance in the Phillips (1974) task. Frame 1 durations of 20 and $500 \mathrm{msec}$ were employed to allow a comparison of performance when visible persistence should be present (20 msec) and when it should be absent $(500 \mathrm{msec})$. Four interframe intervals $(10,200,1,000$, or $5,000 \mathrm{msec})$ were used to assess the time course of recognition memory. If stimulus complexity affects visible persistence, then recognition accuracy for the complex patterns should be higher than recognition accuracy for the simple patterns when a short exposure duration and short interframe intervals are used. If stimulus complexity has no effect on visible persistence, but we have manipulated stimulus complexity effectively, then, as Phillips (1974) has shown, recognition accuracy for the simple patterns should be higher than recognition accuracy for the complex patterns at the long interframe intervals.

\section{Method}

Subjects. Eight subjects participated in this experiment, and each was paid \$3 for each of two 1-h sessions. All subjects reported normal or corrected-to-normal vision.
Apparatus and Stimuli. The apparatus used in the preceding experiments was used in this experiment. The $\mathbf{4 0}$ low-complexity patterns and the 40 high-complexity patterns used in Experiment 5 were used as Frame 1 stimuli. Each pattern contained eight dots arrayed in a $4 \times 4$ matrix of locations. On same trials, the Frame 2 pattern was identical to the Frame 1 pattern. On different trials, the Frame 2 pattern was different from the Frame 1 pattern by the displacement of one dot. Half of the trials were same, and half were different.

The subjects viewed the display from a distance of $33 \mathrm{~cm}$, set by a chinrest. Each dot subtended $0.04^{\circ}$ of visual angle, and the spaces between dots subtended $0.8^{\circ}$ horizontally and $0.9^{\circ}$ vertically. The entire array subtended $2.9^{\circ}$ vertically and $2.6^{\circ}$ horizontally. The stimuli were presented with an effective luminance of $71 \mathrm{~cd} / \mathrm{m}^{2}$; the background luminance was $12 \mathrm{~cd} / \mathrm{m}^{2}$.

Procedure. On each trial, the subjects were presented with one of the Frame 1 patterns for either 20 or $\mathbf{5 0 0} \mathrm{msec}$. Following a variable interframe interval $(10,200,1,000$, or $5,000 \mathrm{msec})$, the second frame of eight dots was presented for $20 \mathrm{msec}$. A $200-\mathrm{Hz}$ tone was presented after Frame 2 offset to signal the subject to respond. The subject reported whether the two patterns were identical or different by typing on the computer terminal keyboard. Stimulus type, Frame 1 duration, and interframe interval varied randomly from trial to trial. Each subject completed two sessions of 320 trials each, constituting 40 trials at each of the two complexity levels, at each Frame 1 duration, and at each interframe interval (i.e., each subject saw each Frame 1 pattern once at each Frame 1 duration and at each interframe interval).

\section{Results and Discussion}

The results of this experiment are shown in Figure 10. Analysis of variance revealed significant main effects of stimulus complexity $[F(1,7)=16.4, p<.01]$, interframe interval $[F(3,21)=18.3, p<.001]$, and Frame $1 \mathrm{du}-$ ration $[F(1,7)=53.9, p<.001]$. In addition, the interaction between stimulus complexity and interframe interval $[F(3,21)=16.7, p<.001]$ and the interaction between Frame 1 duration and interframe interval $[F(3,21)$ $=24.9, p<.001]$ were significant. As in the preceding experiments, the standard error was less than $2 \%$, smaller than the plot symbols in the figure.

The results of this experiment can be summarized as follows. When a short exposure duration $(20 \mathrm{msec})$ was used, accuracy increased as the interframe interval be-

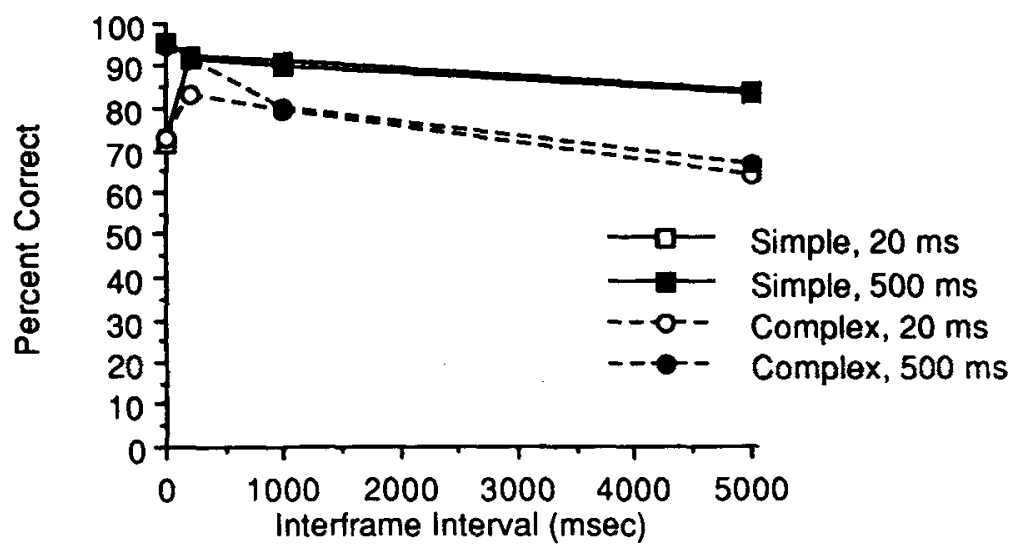

Figure 10. Percent correct as a function of interframe interval for simple and complex patterns presented for exposure durations of 20 and 500 msec in Experiment 6. 
tween the two patterns increased from 10 to $200 \mathrm{msec}$. The accuracy decrement at the 10 -msec interframe interval was caused by visible persistence: the two patterns fused into a single perceptual composite, making it difficult for subjects to tell whether the two patterns were identical or different. Stimulus complexity had no effect on accuracy at the 10-msec interframe interval, indicating that complexity has no effect on visible persistence. At the longer interframe intervals, visible persistence was no longer present. Thus, accuracy was quite high for intervals of 200 to $1,000 \mathrm{msec}$, then declined (but remained above chance) as the interframe interval increased from 1,000 to $5,000 \mathrm{msec}$. Recognition accuracy was higher for simpler patterns than for complex patterns at these longer interframe intervals. Performance at these intervals presumably relies on a limited-capacity visual shortterm memory that represents simple patterns more accurately than complex patterns (Irwin, in press; Phillips, 1974; Turvey, 1978). This kind of memory has been called schematic persistence (Phillips, 1974; Turvey, 1978). When a long exposure duration $(500 \mathrm{msec})$ was used, a similar pattern of results was found, except there was no decrement in performance at the shortest interframe interval. This was because the duration of visible persistence is negligible for stimulus exposures exceeding $100 \mathrm{msec}$.

In summary, Experiment 6 has demonstrated that at least one of the complexity manipulations employed in the preceding experiments affects some form of visual memory. Stimulus complexity appears to have no effect on the duration of visible persistence, however. This finding is inconsistent with the process model of visible persistence.

\section{GENERAL DISCUSSION}

The research reported above was designed to contrast two competing hypotheses about the source of visible persistence: the neural hypothesis, which claims that visible persistence is due to temporal sluggishness in the visual system, and the process hypothesis, which claims that visible persistence is a byproduct of information extraction processes under cognitive control. To discriminate between these hypotheses, stimulus complexity was manipulated in a temporal integration task whose successful performance relies on visible persistence. According to the process hypothesis, complex stimuli should persist longer than simple stimuli because they contain more information; hence, subjects should be able to integrate complex stimuli at longer temporal intervals than simple stimuli in our experimental task. This prediction was disconfirmed in five different experiments. Of special importance is the result that complexity had no effect on the duration of visible persistence even when subjects were required to report the items present in the stimulus display (Experiment 4). This is the very condition in which "visible persistence" had been shown to be significantly longer for complex stimuli than for simple stimuli in other experiments (Erwin, 1976b; Erwin \& Hershenson, 1974). The fact that stimulus complexity had no effect on the duration of visible persistence in our objective integration task suggests that the complexity effects found by others using more subjective techniques arise from some source other than visible persistence; below we discuss several possible sources for these effects. For now, we conclude that visible persistence is not under cognitive control, but rather results from residual activation in the visual pathway following stimulus offset.

Of course, this conclusion rests on the assumption that stimulus complexity was manipulated effectively in our experiments. In Experiment 1, the high-complexity stimuli consisted of random consonants and the low-complexity stimuli consisted of Xs. These stimuli differ according to several definitions of stimulus complexity, including symmetry (Garner \& Clement, 1963), number of interior angles (Attneave, 1957), and redundancy (Shannon \& Weaver, 1949). An array of random consonants is more variable than an array of Xs in terms of the number of letter features and letter identities that it contains, so information extraction and visible persistence should be longer for the random consonant arrays than for the $\mathrm{X}$ arrays if the process hypothesis is correct. No difference in persistence duration was found between these two sets of stimuli, however. In Experiments 2-4, stimulus complexity was manipulated by varying the familiarity of the stimulus elements; integration performance for letters versus pseudoletters was compared in Experiments 2 and 3 , and upright and inverted letters were employed in Experiment 4. Pseudoletters and inverted letters are less familiar and hence more complex than upright letters, so they should persist longer if the process hypothesis is correct. No consistent evidence was found to support this prediction, however. In Experiment 5, visual patterns that had been independently rated as being high or low in complexity were used as stimuli; pattern complexity had no effect on the duration of visible persistence in this experiment, either. This was so even though the same visual patterns did yield a complexity effect on visual short-term memory, or schematic persistence, in Experiment 6. In summary, several different manipulations of complexity were employed, and none of them had a reliable effect on the duration of visible persistence. Furthermore, several of the complexity manipulations that were employed had been found to affect early visual processing when more subjective measures of visible persistence were used. For example, Briggs and Kinsbourne (1972) found that a field of letters "persisted" longer than a field of squares, and Avant et al. (1975) and Erwin (1976b) found that stimulus familiarity affected the apparent duration of a stimulus. These findings suggest that our complexity manipulations should have been effective if visible persistence, when objectively measured, depends upon cognitive processing demands. In summary, it seems unlikely that our failure to find a complexity effect on the duration of visible persistence was due to an inappropriate manipulation of stimulus complexity. 
Why did previous investigators find that complex stimuli appear to persist longer than simple stimuli, whereas we did not? One possibility is that different persistence tasks measure different aspects of visual persistence. Hawkins and Shulman (1979) defined Type I persistence tasks as those that measure visible persistence up to some distinct termination or subjective offset and Type II persistence tasks as those that measure the last lingering trace of a stimulus, past the point of subjective offset. Perhaps the temporal integration technique that we employed is of one type, while all the other tasks that have found evidence for complexity effects on visible persistence are of another type. The major problem with this argument is that there is no a priori way to determine whether any given persistence task is of Type I or Type II. Advocates of the Type I/Type II distinction (e.g., Long, 1985; Nisly \& Wasserman, 1989) have attempted to classify persistence tasks as Type I or Type II on the basis of the kind of data they produce, but this is circular and there are many inconsistencies across experiments (Di Lollo, 1983, 1984; Irwin \& Yeomans, 1986). Consequently, we see little point in pursuing this argument.

Several other potential reasons for the discrepancy between our results and the results of previous investigators present themselves, however. The temporal integration task that we employed is a demanding, objective procedure that can be performed accurately only if a visible trace of the extinguished stimulus persists in the visual system. The same cannot be said for the tasks that have found complexity effects on persistence duration. The onset-offset technique employed by Erwin (Erwin, 1976b; Erwin \& Hershenson, 1974) requires subjects to respond to the offset of a stimulus by pressing a response button; this response is subject to criterion shifts and to interference from other, ongoing cognitive operations. For example, one reason why "persistence" may be longer when report is required than when report is not required in Erwin's task is that the demand to remember the displayed items slows the subject's response to the offset of the display (cf. Turvey, 1978). In other words, the onset-offset task, like the forced-choice task used by Avant and colleagues (Avant \& Lyman, 1975; Avant et al., 1975), may measure the apparent, or subjective, duration of a stimulus, rather than its visible persistence. As described in the introduction, Avant and colleagues found that subjective duration increases as stimulus complexity increases, so this could account for Erwin's findings (Turvey, 1978). Also, it is not obvious that Erwin's task measures only visible persistence and not other forms of persistence as well, such as schematic persistence. The results of Experiment 6 and the results of Phillips (1974) have demonstrated that schematic persistence is affected by stimulus complexity; thus, the effect of complexity in Erwin's task might be due to schematic persistence, rather than to visible persistence. Finally, we should mention that we were unable to replicate Erwin and Hershenson (1974) or Erwin (1976b); using an onset-offset procedure and stimuli like theirs, we obtained identical estimates of persistence duration under report and no-report condi- tions. This is inconsistent with their findings and inconsistent with the process view of visible persistence.

In all likelihood, the other demonstrations of complexity effects on the apparent duration of stimuli are due to one or more of the factors described above, as well. For example, as noted in the introduction, although the Avant et al. (1975) and Avant and Lyman (1975) studies are sometimes cited as supporting the process view of visible persistence (e.g., Long \& Wurst, 1984), Avant and colleagues actually favored an explanation that had nothing to do with visible persistence, based on the finding that the apparent duration differences between stimuli were larger when masks that eliminated visible persistence were presented after stimulus offset. Loftus and Hanna (1989) suggested that complex scenes might persist longer than simple dot patterns, but their task may have measured schematic persistence as well as visible persistence; furthermore, their stimuli differed on physical dimensions such as contrast and luminance, in addition to cognitive dimensions. Briggs and Kinsbourne (1972) found that a display of letters persisted longer than a display of squares, but in fact this difference was not statistically significant. In summary, the evidence supporting the argument that stimulus complexity increases duration of visible persistence is less than compelling.

To conclude, visible persistence appears to be a residual neural trace of an extinguished stimulus, rather than a byproduct of cognitively driven information-extraction processes. It is important to emphasize that the processing view of persistence that we are arguing against is one that says that the duration of visible persistence is under cognitive control. Di Lollo (1980) has proposed a processing theory of visible persistence that holds that persistence is an outcome of sensory coding activity that encodes features of the stimulus array early in the informationprocessing sequence. One phase of processing (the recruiting phase) has virtually unlimited processing capacity and maintains physical aspects of the display (i.e., visible persistence). A second phase of processing (the interpreting phase) has a limited capacity and maintains informational, rather than physical, aspects of a display (e.g., schematic persistence). Although this is a processing model of persistence, it is one in which stimulus complexity affects schematic persistence, rather than visible persistence. Thus, it is entirely compatible with the results of the present research. The conclusion that visible persistence is simply a residual trace of a stimulus is consistent with current physiological models of visible persistence as well (e.g., Duysens, Orban, Cremieux, \& Maes, 1985; Nisly \& Wasserman, 1989). Indeed, it is difficult to imagine a physiological instantiation of the process model of visible persistence. Fortunately, it appears to be unnecessary.

\section{REFERENCES}

AllPort, D. A. (1970). Temporal summation and phenomenal simultaneity: Experiments with the radius display. Quarterly Journal of Experimental Psychology, 22, 686-701.

AtTneave, F. (1957). Physical determinants of the judged complexity of shapes. Journal of Experimental Psychology, 53, 221-227. 
Avant, L. L., Lyman, P. J. (1975). Stimulus familiarity modifies perceived duration in prerecognition visual processing. Joumal of Experimental Psychology: Human Perception \& Performance, 1, 205-213.

Avant, L. L., Lyman, P. J., \& ANTes, J. R. (1975). Effects of stimulus familiarity upon judged visual duration. Perception \& Psychophysics, 17, 253-262.

BoGARTz, R. S. (1990). Evaluating forgetting curves psychologically. Joumal of Experimental Psychology: Leaming, Memory, \& Cognition, 16, 138-148

BreITME YER, B. G., \& GANZ, L. (1976). Implications of sustained and transient channels for theories of visual pattern masking, saccadic suppression, and information processing. Psychological Review, 83, 1-36.

BrIGGS, G., KINSBOURNe, M. (1972). Visual persistence as measured by reaction time. Quarterly Journal of Experimental Psychology, 24, 318-325.

Coltheart, M. (1980). Iconic memory and visible persistence. Perception \& Psychophysics, 27, 183-228.

Di LoLLo, V. (1980). Temporal integration in visual memory. Journal of Experimental Psychology: General, 109, 75-97.

Di Lollo, V. (1983). On laterality of visual aftereffects: A rejoinder. Perception \& Psychophysics, 33, 599-603.

Di LolLo, V. (1984). On the relationship between stimulus intensity and duration of visible persistence. Joumal of Experimental Psychology: Human Perception \& Performance, 10, 144-151.

DI LoLLo, V., HoGBEN, J. H. (1985). Suppression of visible persistence. Joumal of Experimental Psychology: Human Perception \& Performance, 11, 304-316.

Di LoLlo, V., Hogben, J. H. (1987). Suppression of visible persistence as a function of spatial separation between inducing stimuli. Perception \& Psychophysics, 41, 345-354.

Duysens, J., Orban, G. A., Cremieux, J., \& Maes, H. (1985). Visual cortical correlates of visible persistence. Vision Research, 25, 171-178.

ErIKSEn, C. W., \& ColuuNs, J. F. (1967). Some temporal characteristics of visual pattern recognition. Journal of Experimental Psychology, 74, 476-484.

ERIKSEN, C. W., Schultz, D. W. (1978). Temporal factors in visual information processing: A tutorial review. In J. Requin (Ed.), Attention and performance VII (pp. 3-23). Hillsdale, NJ: Erlbaum.

ERWIN, D. E. (1976a). The extraction of information from visual persistence. American Journal of Psychology, 89, 659-667.

ERwIN, D. E. (1976b). Further evidence for two components in visual persistence. Joumal of Experimental Psychology: Human Perception \& Performance, 2, 191-209.

ErwT, D. E., Hershenson, M. (1974). Functional characteristics of visual persistence predicted by a two-factor theory of backward masking. Joumal of Experimental Psychology, 103, 249-254.

Garner, W. R., Clement, D. E. (1963). Goodness of pattern and pattern uncertainty. Journal of Verbal Learning \& Verbal Behavior, 2, 446-452.

Hawkins, H. L., \& Shulman, G. L. (1979). Two definitions of persistence in visual perception. Perception \& Psychophysics, 25, 348-350.
Hogben, J. H., \& Di Lollo, V. (1974). Perceptual integration and perceptual segregation of brief visual stimuli. Vision Research, 14, 1059-1069.

ICHIKAWA, S. (1985). Quantitative and structural factors in the judgment of pattern complexity. Perception \& Psychophysics, 38, 101-109.

IRwIN, D. E. (in press). Visual memory within and across fixations. In K. Rayner (Ed.), Eye movements and visual cognition: Scene perception and reading. New York: Springer-Verlag.

IrWIN, D. E., Yeomans, J. M. (1986). Persisting arguments about visual persistence: Reply to Long. Perception \& Psychophysics, 39. 225-230.

LoFTUS, G. R. (1985). Evaluating forgetting curves. Joumal of Experimental Psychology: Leaming, Memory, \& Cognition, 11, 397-406.

LofTUS, G. R., * BAMBER, D. (1990). Leaming-forgetting independence, unidimensional memory models and feature models: Commentary on Bogartz (1990). Joumal of Experimental Psychology: Learming. Memory, \& Cognition, 16, 916-926.

Loftus, G. R., HanNA, A. M. (1989). The phenomenology of spatial integration: Data and models. Cognirive Psychology, 21, 363-397.

LoFTUS, G. R. , HoGDEN, J. (1988). Extraction of information from complex visual stimuli: Memory performance and phenomenological appearance. In G. H. Bower (Ed.), The psychology of learning and motivation (Vol. 22, pp. 139-191). San Diego: Academic Press.

LoNG, G. M. (1980). Iconic memory: A review and critique of the study of short-term visual storage. Psychological Bulletin, 88, 785-820

LoNG, G. M. (1985). The varieties of visual persistence: Comments on Yeomans and Irwin. Perception \& Psychophysics, 38, 381-385.

LoNG, G. M., \& WURst, S. A. (1984). Complexity effects on reactiontime measures of visual persistence: Evidence for peripheral and central contributions. American Joumal of Psychology, 97, 537-561.

Matin, E. (1975). The two-transient (masking) paradigm. Psychological Review, 82, 451-461.

Nisly, S. J., \& Wasserman, G. S. (1989). Intensity dependence of perceived duration: Data, theories, and neural integration. Psychological Bulletin, 106, 483-496.

PHILLIPs, W. A. (1974). On the distinction between sensory storage and short-term visual memory. Perception \& Psychophysics, 16, 283-290.

ShanNon, C. E., WeAver, W. (1949). The mathematical theory of communications. Urbana: University of Illinois Press.

TURVEY, M. T. (1978). Visual processing and short-term memory. In W. K. Estes (Ed.), Handbook of learning and cognitive processes (Vol. 5, pp. 91-142). Hillsdale, NJ: Erlbaum.

Weisstein, N., Ozog, G., Szoc, R. (1975). A comparison and elaboration of two models of metacontrast. Psychological Review, 82, 325-343.

(Manuscript received April 11, 1990; revision accepted for publication June 17, 1991.) 